\title{
Sleep and Breathing an international conference in Prague, Czech
Republic from March 31 to April 2, 2011
}

Don't miss Prague in the spring!

Further information about the programme and registration details can be found at www. sleepandbreathing.org

An exciting new venture will take place in Prague, Czech Republic in Spring 2011 when the first international Sleep and Breathing conference takes place between March 31 and April 2. The conference is jointly organised by the European Respiratory Society (ERS) and the European Sleep Research Society (ESRS). This event, which is the first in a planned series of conferences, will provide a unique forum for education and training of healthcare professionals in the field of respiratory sleep disorders, and will further intensify the relationship and interactions between sleep and respiratory physicians and scientists. The series will highlight the central role of respiratory sleep disorders in clinical sleep medicine and will also increase awareness about sleep disorders and sleep science among respiratory physicians and, respectively, of sleep-disordered breathing and respiratory physiology among nonrespiratory physicians and scientists. The Hot Topics include cardiovascular and metabolic consequences of sleep apnoea, in addition to genetic factors. These aspects help define the clinical consequences and pathophysiological basis of the disorder.

The conference fills an important gap between major international respiratory (e.g. ERS and the American Thoracic Society) and sleep (e.g. ESRS and the American Academy of Sleep Medicine) society congresses and small educational seminars, such as ERS School Courses. To my knowledge, this event represents the only mid-size conference anywhere in the world with an educational focus on the topic of Sleep and Breathing. The conference will provide a comprehensive coverage of the field with a predominant educational focus, and will include a broad spectrum of participation for delegates ranging from platform lectures, interactive case studies and Meet the Professor sessions, together with practical "hands-on" training sessions. There will also be poster discussion sessions where delegates can present their own local research, and these will have a strong clinical focus. Over 90 abstracts have been selected for presentation at the conference. Since many respiratory physicians and scientists, and ERS members do not attend the ESRS Congress, the Prague Sleep and Breathing conference will also offer a unique opportunity for an interaction between respiratory and nonrespiratory physicians and scientists interested in sleep, as well as between ERS and ESRS members.

A major result of the conference should be an enhanced appreciation of the clinical importance of sleep and breathing disorders among respiratory clinicians in addition to more knowledge about sleep among respiratory physicians and about respiratory disorders among nonrespiratory clinicians and scientists. The conference will bring experts in sleep and breathing disorders together with clinical practitioners, and should improve the expertise of clinical practitioners in this field. Sleep disorders are highly topical and a source of concern among the general public, as evidenced by the high level of coverage of this topic in various media. The growing data on the link between sleep disorders and cardiovascular risk, but also between sleep disorders and neurological and psychiatric disorders, and between sleepiness and accidents, has drawn attention to the importance of diagnosis and management of sleep disorders in the general population.

\section{W.T. McNicholas}

Pulmonary and Sleep Disorders Unit, St Vincent's University Hospital, Elm Park, Dublin 4, Ireland

walter.mcnicholas@ucd.ie

\section{Competing interests}

None declared. 